Tracking and Tracing Stolen Assets in Foreign Jurisdictions

Charles Monteith | Andrew Dornbierer
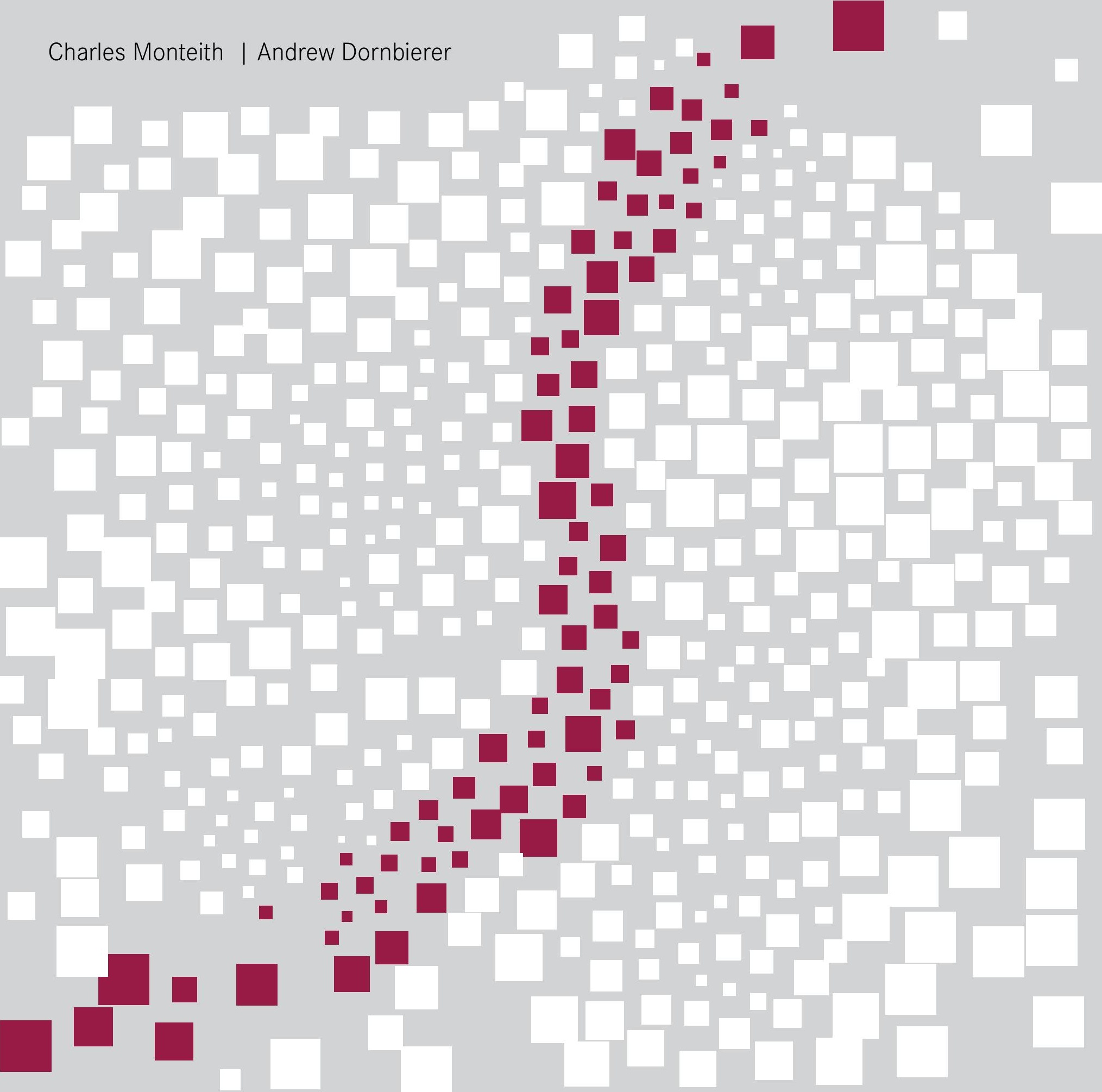
Basel Institute on Governance Working Paper 15. ISSN: 2624-9650.

(C) Basel Institute on Governance

Responsibility for the views expressed and for any errors of fact or judgment rests with the authors alone.

This paper apeared in eucrim, the European Criminal Law Associations' Forum, 2013/2, published by Max Planck Society for the Advancement of Science c/o Max Planck Institute for Foreign and International Criminal Law, Freiburg i. B., Germany. 


\section{Tracking and Tracing Stolen Assets in Foreign Jurisdictions}

Charles Monteith | Andrew Dornbierer 
2. THE MULTIFACETED PURPOSE OF AN ASSET TRACING INVESTIGATION 10

3. ESTABLISHING THE ILLEGALITY OF FUNDS 11

4.COMMON BARRIERS FACED WHEN SEEKING STOLEN ASSETS

6. CONCLUSIONS - WHERE TO NOW FOR ASSET TRACING 16 


\section{About the authors}

Charles Monteith is Head of Legal and Case Consultancy at the International Centre for Asset Recovery (ICAR). Prior to joining ICAR, he worked as Counsel for White and Case providing advice, strategy and training on corporate compliance and anti-bribery matters. He was also formally Head of Assurance at the UK Serious Fraud Office (SFO) where he was a key architect of the UK Bribery Act and, on the Law Commission's Bill Advisory Group, led the drafting of the Attorney General's guidelines. Charlie has many years' experience in prosecuting serious crime, including high-profile cases.
Andrew Dornbierer is a researcher for the Basel Institute on Governance. A qualified lawyer in Australia, Andrew predominantly works for the Legal \& Case Consultancy team within the International Centre for Asset Recovery (ICAR). Andrew graduated from the University of Western Australia and holds degrees in both law and international relations. He has completed internships at several international NGOs, including the United Nations Crime and Justice Research Institute in Turin, Italy. 



\section{Introduction}

It has been estimated that roughly 1.6 trillion USD in criminal proceeds are laundered through the international financial system each year. ${ }^{1}$ To put this in perspective, this sum is more than the combined GDPs of Switzerland, Portugal, Romania, Belarus, and Austria in 2011. To enjoy this unnerving amount of illicit assets, criminals are forced to launder these funds through legitimate international financial channels in an attempt to disguise their illegitimate origins. Consequently, if an investigator knows how and where to look, there is always a connection that links a criminal's assets to his or her crimes - and if sufficient evidence of this connection can be shown, then law enforcers can use it to successfully take legal action and return the assets to the victims of their crime.
For this reason, it is very important that effective asset tracing tools and techniques are developed and shared amongst law enforcement bodies to help stem the tide of illicit financial flows, deny criminals the chance to enjoy the proceeds of their crime, and ultimately, to achieve justice.

This article will discuss some of the common techniques and tools used by investigators to track and trace stolen assets. It will focus predominantly on a context whereby funds have been stolen through public corruption. However, the principles discussed in this article are also applicable to most cases in which criminally obtained assets have been laundered into foreign jurisdictions. 


\section{The multifaceted purpose of an asset tracing investigation}

Asset tracing refers to the process whereby an investigator tracks, identifies, and locates proceeds of crime. Asset tracing can be conducted by a number of parties, including law enforcement authorities, prosecutors, investigating magistrates, private investigators, or interested parties in private civil actions. This article however, will primarily focus on the context of an investigation conducted by government law enforcement authorities. Investigators in these authorities trace assets for the purpose of freezing and seizing them, so that these assets can ultimately be confiscated through a judicial order and returned to the victims of crime, be that a private party or the state.

Consequently, asset tracing investigations are a multifaceted activity, and they must accomplish more than simply locate a criminal asset. Investigators also need to acquire sufficient evidence to connect the asset to an unlawful activity so that a judicial order for confiscation can be obtained. At the same time, investigators should also try to gather evidence that can be used to prosecute the offender for the underlying criminal activity (or predicate offence) that generated the illicit assets.
In an asset tracing investigation, these three objectives locating the assets, linking them to a unlawful activity, and proving the commission of the offence - should not be considered as three distinct and separate steps but as overlapping objectives that investigators should work towards achieving simultaneously, for the purpose of achieving a final goal: to deny criminals of the proceeds of their crime. 


\section{Establishing the illegality of funds}

From the outset, it is is very important that investigators conducting an asset tracing exercise always remember that even if they find the assets, a jurisdiction where funds have been secreted will not confiscate or repatriate these funds to the jurisdiction of origin unless actual evidence is presented linking the funds to an illicit source. Consequently, throughout the entire investigation, emphasis needs to be placed on establishing that the funds being sought are undoubtedly illegal in origin. This can be done directly, through specific proof establishing criminal activity (such as a recording of a bribe) or, alternatively, indirectly through circumstantial evidence.
One particular indirect approach is to apply the Source and Application Method. ${ }^{2}$ The basic theory of this method is to establish that the person under investigation spent far more money during a set period of time than is legally available to them. Take, for example, a case in which there is an investigation into a corrupt public official who has been taking bribes from corporations in return for granting procurement contracts. When establishing the illegality of this official's assets, investigators can indirectly establish that he received more money during his time in office than was afforded to him by his salary by listing all his known assets (savings balances) and expenses (living expenses, major purchases) during that same period, and subtracting the total official income he received. If, after this subtraction, there is still money remaining and the source of this money cannot be explained, this indirectly suggests that these funds must have come from an illicit source (in this case, bribery). This will go a long way towards securing a criminal conviction for his bribery offences, which will in turn lead to a successful confiscation of his criminally obtained assets. 


\section{Common barriers faced when seeking stolen assets}

Unfortunately, when it comes to tracking and identifying the proceeds of crime, enforcement authorities can face many hurdles. Criminals are becoming increasingly skilled at developing new and innovative ways to disguise illegally obtained assets, and the complex nature of even the most common money laundering techniques can generate problems for investigators.

For instance, the obvious fact that assets can take a multitude of different forms can make them very difficult to track. Assets can easily be converted into many tangible and intangible forms (including physical or digital money, corporate stocks or market investments, real property, moveable property with objective value - such as cars or boats - or a subjective value - such as jewelry and works of art, or even educational scholarships). Furthermore, the widespread use of e-money currencies such as Bitcoins (an Internet-based currency often used in online black market transactions) and even traditional cash (e.g., in cross-border transaction schemes such as Hawalla systems) poses enormous problems for investigators due to their difficulty to track. Consequently, the multiple forms assets can take means that investigators must have an understanding of a wide range of spheres, including financial markets, corporate and commercial structures, banking practices, property and insolvency law, and online currencies in order to successfully trace the path of a converted asset.

Difficulties can also arise in determining the beneficial owner of illicit assets. For example, criminals can adopt a number of techniques to disguise their ownership, including putting assets in the name of family, friends, or close associates, or setting up intricate structures of special purpose vehicles, such as shell companies and trusts. By cleverly disguising ownership and by adding layers of complexity to money laundering schemes, criminals can make it extremely difficult for investigators, firstly, to locate their concealed assets and, secondly, to establish enough evidence to prove actual beneficial ownership of these proceeds of crime.
Furthermore, as most stolen assets cases are international in nature and involve multiple jurisdictions, this creates a long list of barriers surrounding the effective interaction and cooperation of state intelligence gathering and law enforcement agencies. For example, problems in communication can arise when two jurisdictions use different languages and issues of coordination may result from dissimilarities in institutional structures. Moreover, stark contrasts in legal systems or approaches to criminality (as represented by the recognition of certain criminal acts as predicate offences to money laundering or the punishment foreseen for the commission of these offences) may also serve to hinder an investigation and a subsequent prosecution.

Overall, in most cases, tracing stolen assets is not an easy task. Nevertheless, different practices and tools can assist law enforcement authorities in their efforts to disentangle money laundering schemes and can vastly increase the chances of a successful repatriation. 


\section{The investigator's toolkit for tracing assets}

The success of an investigation often largely depends on the investigating authority's ability to utilize all the tools available to it for tracing assets. The types of tools vary in nature and can include specialized investigating agencies such as Financial Intelligence Units (FIUs), different sources of intelligence, as well as strategies of cooperation with foreign enforcement agencies. ${ }^{3}$

\section{Financial Intelligence and FIUs}

When assets flow through the financial system, the transfer of funds in and out of accounts usually leaves an audit trail, which can be tracked and detected. Financial intelligence refers to any data that can be obtained to assist in this discovery process and can ultimately be used to create the financial profile of a suspect. This data can come from a wide range of sources and can include information obtained from financial institutions (such as account statements, account opening information, and suspicious activity reports), government agencies, e-banking facilities, money service providers, law and accounting firms, real estate agents, trust and company service providers, and business competitors.

To assist in collating such data, FIUs have been established in most jurisdictions around the world. Primarily, they receive, analyze, and disclose information provided by financial and non-banking financial institutions relating to suspicious or unusual financial transactions, but they also build up profiles of individuals and money laundering techniques. ${ }^{4}$ Furthermore, in 1995, the Egmont Group of Financial Intelligence Units was created, which provides a forum within which the FIUs of different states can share financial intelligence relevant to suspects being investigated in different jurisdictions, thus greatly speeding up international coordination efforts.

3 J. Brun. L. Gray, C. Scott and K. Stephenson, Asset Recovery Handbook: A Guide for Practitioner's, the World Bank, 2011.
To illustrate the importance of financial intelligence, imagine again an example in which the law enforcement agency of a jurisdiction is investigating a former public official on charges of accepting bribes. When establishing both the location of the stolen money and the fact that bribery has taken place, investigators (or their intelligence services via the FIUs) can use financial intelligence to locate the bank accounts of the public official (or those of his close family or associates) to determine whether any unusual transfers have been received in these accounts and whether any subsequent suspicious transfers have been sent out of these accounts (including the location of any further institutions involved in these transfers). Furthermore, financial intelligence sources can also be used to determine the existence of any corporate or trust holdings or whether any major property purchases have taken place on behalf of the corrupt official.

\section{Human intelligence}

Human intelligence sources remain one of the key intelligence tools for law enforcement agencies, particularly when dealing with money laundering networks that are very difficult to penetrate. Human intelligence encompasses all instances in which an individual comes forward and provides information that can assist in the investigation and generally refers to informants, whistleblowers, victims, or disgruntled co-conspirators. The information provided by such intelligence can be critical to a successful investigation, as it can provide inside information into criminal networks as well as new directional leads that may result in the gathering of further incriminating evidence.

However, while the information provided by such individuals can be invaluable, it is important to exercise a considerable level of caution, particularly when evaluating the motives of the individual providing such information, as misleading or wrong information can compromise and taint an entire investigation. 
To apply this to the example of the corrupt public official mentioned above, human intelligence may take the form of a whistleblower within the official's ministry or the irritated directors of a corporation that has lost out to competitors because they refused to give a bribe. In this example, the information from such human intelligence may assist in establishing that an offence of bribery has taken place and may also assist investigators in following assets by, for example, providing information pertaining to the method through which bribes are accepted. Nevertheless, it is important to remember that, as with all such human intelligence sources, investigators must take care to verify the integrity of any information that is offered so as to rule out any chance that the information may taint the investigation.

\section{Open sources of intelligence}

A particular source of intelligence that has been increasingly utilized in the past decade is open source intelligence, which involves the acquisition and analysis of information from publicly available sources. For instance, due to the exponential growth of the Internet, an increasing amount of sources are becoming publicly available - providing investigators with a wealth of high-quality evidence that can be used to support strategic and operational decisions. Examples of such sources include online media (newspapers, blogs, etc.), directories, government reports and documents (including asset declaration forms), statistical databases, and publicly available databases (such as property and corporate databases), which can all be easily located using publicly available search engines, such as Google, or analyzed using specifically tailored programs, such as the International Centre for Asset Recovery (ICAR) Asset Recovery Intelligence System (ARIS) tool. ${ }^{5}$

Social media websites are an online open source that has been of particular use to investigators in recent years. Facebook and LinkedIn, for instance, have become a rich source

5 For more information on ARIS, please visit the Basel Institute on Governance's website: http://www.baselgovernance.org/icar/it-services. of information, as they can provide a detailed insight into an individual's contacts and movements and, on some occasions, even his or her major purchases. For instance, returning to the example of our corrupt public official, an investigator may be able to acquire a great deal of valuable information by examining the Facebook profile of this public official or, if he does not have one, the profile of his wife, children, or known contacts. During the course of such analysis, investigators may discover photos of holidays that this public official has taken with his family, including pictures displaying assets such as recently purchased cars or holiday homes. The location of such pictures may further indicate the jurisdictions in which these assets could be found and seized.

\section{Cooperation with foreign enforce- ment agencies}

When assets are situated in foreign jurisdictions, enforcement agencies can cooperate with foreign counterparts to both obtain information and evidence pertaining to the location of assets as well as to actually have the assets frozen and seized.

For instance, if we imagine that our corrupt official has transferred his criminally obtained assets from a bank account in his own country (A) to an account in a second country (B) and then into an account in a third country $(C)$, the law enforcement agents in $(A)$ will require cooperation from the enforcement agencies of both these latter countries. Particularly, cooperation with (B) will be necessary in order to investigate the trail of assets and to establish that the assets have been moved into (C), and cooperation from (C) will be necessary to ultimately freeze and seize the assets located there.

In initially tracing the path of the assets, the investigators in (A) could informally exchange information with the enforcement agencies from (B). For instance, if both countries have an FIU that is a member of the Egmont Group, they 
can utilize this network and its mechanisms to allow for the informal and rapid exchange of information regarding the suspicious assets. Alternatively, if each state is a member of the Camden Assets Recovery Interagency Network (CARIN) or another similar network, such as the Asset Recovery Inter-Agency Network of Southern Africa (ARINSA), they could utilize them to also informally share and receive information. This would allow (B) to quickly inform (A) of the transfer of the assets to $(C)$. As a result, $(A)$ would be able to contact $(C)$ to informally request that a preliminary freeze be put on the suspicious assets to prevent them from being moved again.

However, in order to seize the suspicious assets, (A) will need to ask $(C)$ to do so through a request for mutual legal assistance (MLA). MLA is a means through which one jurisdiction formally provides assistance to competent authorities (such as prosecutors, magistrates, and even law enforcement agents) in another jurisdiction so that the former may have certain investigatory or judicial acts (such as service of process, evidence, or seizure of assets) recognized, processed, and carried out in the latter, as the authorities of the requesting jurisdiction do not have the legal standing to enforce them in the requested jurisdiction. Thus, if prosecutors in $(A)$ wish to use evidence (such as bank statements) located in (B) or (C) in a criminal proceeding in (A) against the public official, they will also need to extract this evidence through a formal request for MLA in order to ensure that this evidence is admissible during legal proceedings.
Overall, the ability of law enforcement agencies to engage and cooperate with foreign counterparts may make or break an asset tracing effort. For instance, the ability of investigating agencies to quickly exchange intelligence at the beginning of an investigation can greatly affect their ability to ultimately "catch up" and seize the illegally obtained assets, while the execution of timely and well-drafted MLAs can be crucial to gathering sufficient evidence in order to obtain orders for confiscation. Fortunately, an increasing number of enforcement agencies are establishing international agreements (be it state-to-state cooperation agreements, inter-agency cooperation agreements, mutual legal assistance agreements, or joining international information sharing networks such as Egmont and CARIN), and this is greatly assisting international efforts to trace and recover assets both at the informal and at the formal levels. 


\section{Conclusions - Where to now for asset tracing?}

There is no doubt that the ability of enforcement agencies to track and trace stolen assets is improving. However, there is certainly still a great deal of room for improvement. This year marks the tenth anniversary of the United Nations Convention Against Corruption, which has been instrumental in raising the awareness of issues relating to asset recovery over the past decade. While many countries have ratified and implemented their obligations under this convention, there is still a significant number who have yet to utilize the potential of UNCAC to assist them in asset tracing efforts.
Criminals are always finding new ways to conceal their assets, and investigators need to use all the tools at their disposal if they are to continue to discover and crack money laundering schemes. While intelligence sources are crucial to investigations, the multijurisdictional nature of most asset tracing cases means that effective international cooperation plays an equally important role. Consequently, in order to further develop and improve asset tracing techniques, state enforcement authorities need to focus on building relationships of trust with their foreign counterparts and on enhancing their ability to exchange information quickly and efficiently. 


\section{Notes}





\section{Basel Institute on Governance}

The Basel Institute on Governance is an independent notfor-profit competence centre specialised in corruption prevention, public and global governance, corporate governance and compliance, anti-money laundering, criminal law enforcement and the recovery of stolen assets. The Institute's multidisciplinary and international team works around the world with public and private organisations towards its mission of tangibly improving the quality of governance globally in line with relevant international standards and good practices.

\section{International Centre for Asset Recovery}

The International Centre for Asset Recovery (ICAR) was established in 2006 by the Basel Institute on Governance, and to date remains one of the world's only two not-forprofit organisations dedicated to recovering stolen assets. ICAR's mission is to strengthen the capacities of developing and transition partner countries to recover stolen assets.

We achieve this mission through training, casework, legal and policy analysis, the development of integrated IT tools, and active contributions to the global policy dialogue and international standard setting in asset recovery. ICAR is funded with core contributions from the Principality of Liechtenstein, the Swiss Development Cooperation and the UK Department for International Development, and through project specific grants.

Beyond close collaboration with these three countries, ICAR works regularly with key international organisations, such as Egmont, Interpol, OSCE, StAR, UNICRI and UNODC.

\section{Working papers}

In this working paper series the Basel Institute on Governance publishes reports by staff members and invited international experts, covering critical issues of governance theory and practice. For a list of publications, please visit www.baselgovernance.org. 
Basel Institute on Governance

Steinenring 60

4051 Basel, Switzerland

www.baselgovernance.org

info@baselgovernance.org

\section{Abstract}

It has been estimated that roughly 1.6 trillion USD in criminal proceeds are laundered through the international financial system each year. To put this in perspective, this sum is more than the combined GDPs of Switzerland, Portugal, Romania, Belarus, and Austria in 2011. To enjoy this unnerving amount of illicit assets, criminals are forced to launder these funds through legitimate international financial channels in an attempt to disguise their illegitimate origins. Consequently, if an investigator knows how and where to look, there is always a connection that links a criminal's assets to his or her crimes - and if sufficient evidence of this connection can be shown, then law enforcers can use it to successfully take legal action and return the assets to the victims of their crime. 